\title{
Clues to recognition of kidney disease in archeologic record: characteristics and occurrence of leontiasis ossea
}

\section{Alterazioni scheletriche in corso di malattie renali croniche: caratteristiche e frequenza della leontiasi ossea e sua importanza in osteoarcheologia}

\author{
C. Rothschild ${ }^{1}$, B. Rothschild ${ }^{1,2}$, I. Hershkovitz ${ }^{3}$ \\ ${ }^{1}$ Arthritis Center of Northeast Ohio and Northeastern Ohio, Universities College of Medicine, Youngstown, Ohio, USA; \\ ${ }^{2}$ Carnegie Museum of Natural History, Pittsburgh, PA, USA and University of Kansas Museum of Natural History, Lawrence, KS, USA; \\ ${ }^{3}$ The Cleveland Museum of Natural History, Cleveland, Ohio, USA and Department of Anatomy and Anthropology, \\ Sackler Faculty of Medicine, Tel Aviv, Israel
}

\begin{abstract}
RIASSUNTO
Le modificazioni dell'apparato osteoscheletrico associate a nefropatie croniche sono state studiate in un campione (94 scheletri) della Haman-Todd Collection (Cleveland, USA), con lo scopo di definire le caratteristiche peculiari di queste, come analisi preliminare di indagini di osteoarcheologia. Particolare attenzione è stata rivolta alla frequenza ed alla localizzazione delle cisti ossee, delle alterazioni delle superfici articolari, dei fenomeni di riassorbimento subperiostale e di porosità, di osteocondrite, così come alle modificazioni della falange ungueale ed agli aspetti di reazione proliferativa periostale.

Lo studio è stato condotto avvalendosi anche di indagini radiologiche e confrontando i dati con un gruppo di controllo.

Si è dimostrato che la tipologia delle alterazioni della superficie articolare e della reazione periostale può essere utile a porre diagnosi di malattia renale su campioni scheletrici. Ancora, manifestazioni suggestive di leontiasi ossea possono essere presenti: queste sarebbero caratterizzate da ispessimento delle ossa del cranio, con aumentate dimensioni e peso, ma senza diastema, se non in rari casi. Comuni invece sarebbero lesioni di tipo "pseudo-osteomatoso".
\end{abstract}

Reumatismo, 2002; 54(2):133-143

\section{INTRODUCTION}

The paucity of reports on renal disease in the archeologic literature seems remarkable, given the prominence of renal disease as a cause of death (1). Renal insufficiency allows waste products to accumulate, calcium loss, and reduced kidney hydroxylation of vitamin $\mathrm{D}$, resulting in renal osteodystrophy. The latter describes a combination of osteomalacia (referred to as rickets in subadults) and hyperparathyroid bone disease (2). The combination of hyperparathyroidism and osteomalacia produces a very characteristic osseous picture, at least radiologically (2). While these changes may be well recognized in contemporary patients on dialysis (3-5), it is unclear how often the non-dia-

Indirizzo per la corrispondenza:

B. M. Rothschild, Arthritis Center of Northeast Ohio, 5500 Market Street, Youngstown, Ohio 44512, USA, E-mail: bmr@neoucom.edu lyzed person (analogous to individuals from archeologic sites) survives long enough for these findings to be observed (6). The aim of this project was to characterize the osseous lesions in individuals diagnosed in life with chronic renal failure and to examine the corollary question - can kidney disease be recognized from examination of skeletons?

\section{METHODS}

The study population includes 94 individuals from the Hamann-Todd Collection. This human skeletal portion of the Todd Collection (Cleveland Museum of Natural History) was compiled by Dr. T. Wingate Todd. These complete skeletons were derived from cadavers of unclaimed status which, after autopsy, were subjected to de-fleshing (with sodium hydroxide to remove soft tissues).

The individuals were selected on the basis of clinical diagnosis during life of chronic renal disease. 
The skeletons were subjected to macroscopic visual examination to identify all occurrences of osseous alterations throughout each skeleton, to specify the types of bony alterations at each occurrence, and to map the distribution of occurrences in each individual. In the event of disagreement as to whether a lesion represented true pathology or artifact, for the purpose of this study it was treated as artifact. A "control" group was obtained by examination of 50 additional consecutive individuals from the Hamann-Todd Collection, who had diagnoses not known to be associated with renal disease, hypertrophic osteoarthropathy, rheumatoid arthritis or spondyloarthropathy $(2,7)$.
Fluoroscopy of all elements of all skeletons was performed using the Xi Scan 1000 fluoroscopy/digital storage system (X-Tech Inc, Randolph, N.J.). Radiographs were obtained with the bones arranged and oriented approximately as they would be in living patients.

\section{RESULTS}

The 94 adult individuals with chronic renal disease included 61 white males, 18 black males, 2 white females and 13 black females. The average age at death was 57.

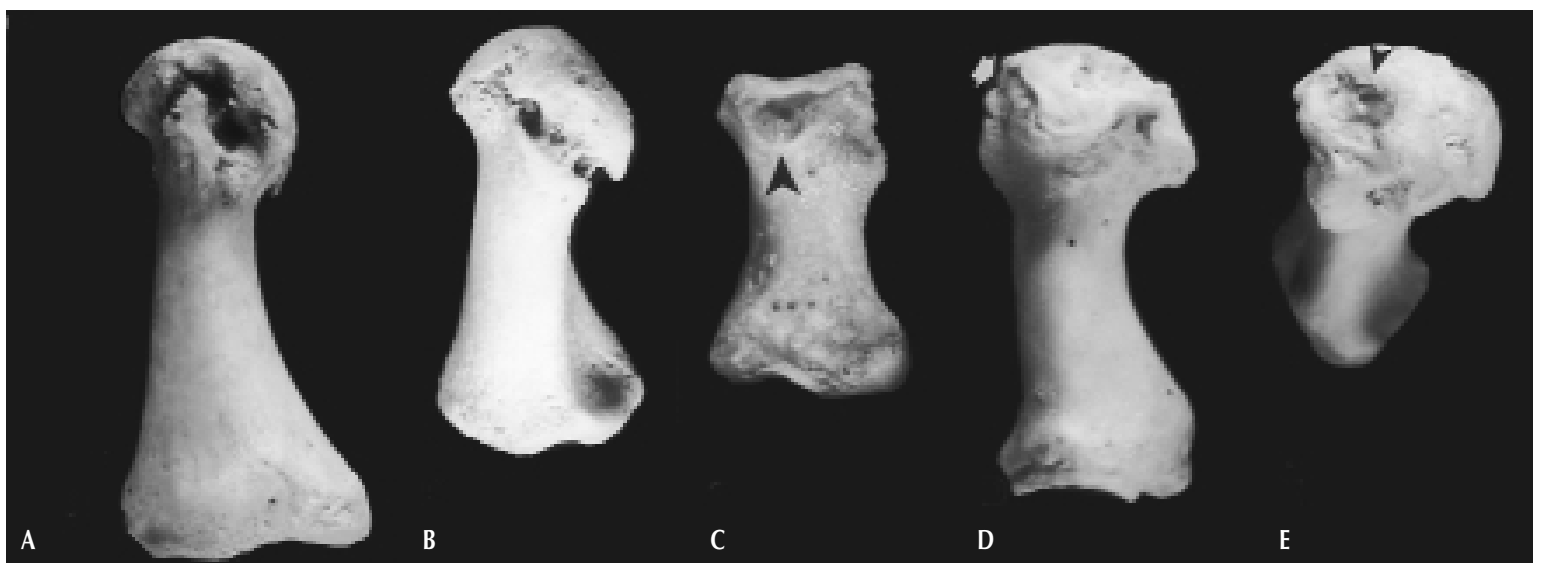

Figure 1 - Erosive disease (arrows) of metatarsal phalangeal (A,B,D,E) and interphalangeal (C) joints. Marginal distribution of erosions in $A, B$, C. Subchondral erosions with "smudged" appearance in D and E. Spheroid erosion in C is highly suggestive of gout.

Table I - Macroscopic joint alterations (\%) in skeletons of individuals diagnosed in life with renal disease/Controls*.

\begin{tabular}{|c|c|c|c|c|c|c|c|}
\hline \multirow{2}{*}{$\begin{array}{l}\text { Observation } \\
\text { joint }\end{array}$} & \multirow{2}{*}{$\begin{array}{c}\text { Surface } \\
\text { calcification }\end{array}$} & \multicolumn{3}{|c|}{ Erosions } & \multirow{2}{*}{$\begin{array}{c}\text { Space } \\
\text { occupying }\end{array}$} & \multirow{2}{*}{$\begin{array}{c}\text { Overhanging } \\
\text { edge }\end{array}$} & \multirow{2}{*}{$\begin{array}{c}\text { Reactive new } \\
\text { bone }\end{array}$} \\
\hline & & marginal & subchondral & crumbling & & & \\
\hline Shoulder & $33 / 2$ & $25 / 4$ & 4 & 3 & 8 & 2 & 13 \\
\hline Elbow & 28 & 5 & 2 & 2 & 1 & 5 & 4 \\
\hline Wrist & $11 / 2$ & 16 & 1 & 4 & 2 & 3 & 5 \\
\hline $\mathrm{MCC}^{* *}$ & 6 & 7 & 3 & 4 & 2 & 4 & 3 \\
\hline MCP** & 3 & $13 / 4$ & 1 & 2 & 3 & 5 & 7 \\
\hline PIP** & 2 & 3 & 2 & 2 & 0 & 0 & 7 \\
\hline DIP** & 1 & 3 & 1 & 2 & 0 & 3 & 4 \\
\hline Hip & 14 & 3 & 1 & 2 & 0 & 3 & 2 \\
\hline Knee & $38 / 8$ & 1 & 2 & 3 & 0 & 2 & 2 \\
\hline Ankle & $14 / 2$ & 4 & 4 & 0 & 4 & 5 & 6 \\
\hline MTP** & 8 & 14 & 6 & 9 & 11 & 16 & 9 \\
\hline $\mathrm{IP}^{* *}$ & 2 & 3 & 2 & 3 & 4 & 8 & 2 \\
\hline
\end{tabular}


Table II - Macroscopic distribution of bone and joint alterations: percent of individuals with specific finding in renal disease/Controls*

\begin{tabular}{|c|c|c|c|}
\hline $\begin{array}{c}\text { Observation } \\
\text { Number of bones/joints affected }\end{array}$ & Erosions & Osteochondritis & Periosteal reaction \\
\hline 1 & $44 / 8$ & 55 & $34 / 2$ \\
\hline 2 & 31 & 19 & $23 / 4$ \\
\hline 3 & 13 & 11 & $20 / 2$ \\
\hline 4 & 6 & 4 & 15 \\
\hline 5 & 1 & 7 & 6 \\
\hline 6 & 0 & 4 & 0 \\
\hline 7 & 0 & 0 & 1 \\
\hline 13 & 0 & 0 & 1 \\
\hline
\end{tabular}

\section{Macroscopic observations \\ Erosions}

Excluding individuals with recognized causes (rheumatoid arthritis and spondyloarthropathy) of erosive disease, a high frequency of joint erosions was still noted (Fig. 1). Both marginally (39 occurrences) and subchondrally distributed erosions (21 occurrences) were present, with crumbling changes in 21 individuals (Table I). In 94\% of individuals, erosions were pauciarticular (Table II).

\section{Cysts and Surface Calcification}

Cysts were infrequently (only 5) recognized on macroscopic examination and geodes (giant cysts), in only 2 individuals. Calcium joint surface deposits (Fig. 2) were present in 57 individuals, distributed as indicated in Table I.

\section{Subperiosteal resorption and porosity}

Subtle macroscopic resorptive changes (Fig. 3) were present in 18 individuals, with porosity in 16 (Table III). Porosity was predominantly (61\%) epiphyseal in distribution. It was an isolated finding in $73 \%$ of afflicted bones. The distal clavicle was affected in $60 \%$ of individuals. It was the only area containing porosity in $45 \%$ of individuals. Only one individual had more than 3 bone groups (e.g., phalanges, femur, tarsals) affected. Subperiosteal resorption was noted in $25 \%$ of bones with porosity and periosteal reaction in $16 \%$ of bones with porosity.

\section{Osteochondritis}

Osteochondritis (Fig. 4) was present in 4 individuals as isolated phenomenon (two elbows, one wrist and one interphalangeal joint). Space-occupying lesions were present in 18 individuals, with

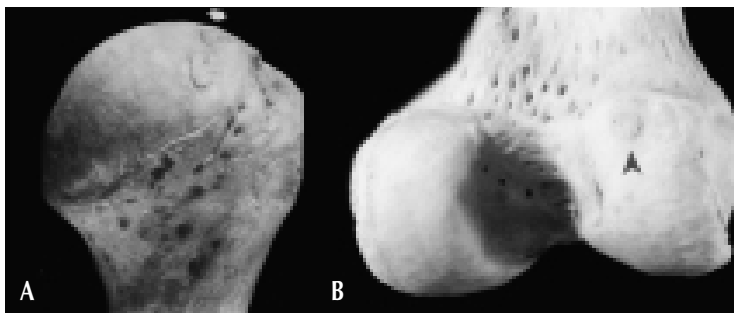

Figure 2 - Calcium joint surface deposits (arrows) on shoulder (A) and knee (B).

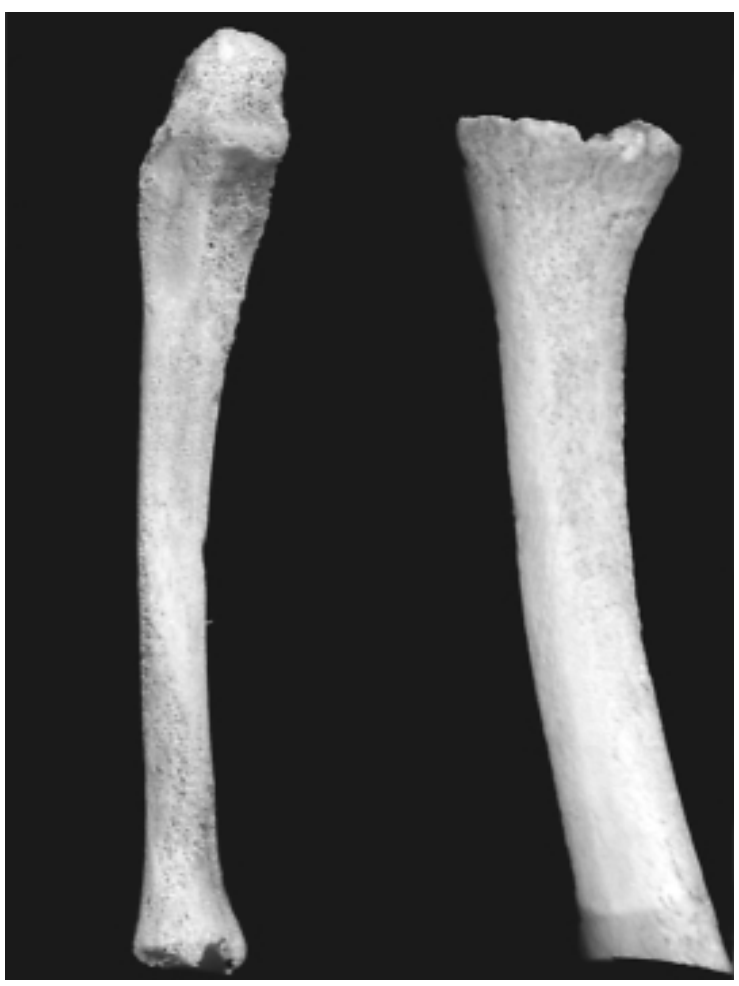

Figure 3 - Subperiosteal resorption on ulna and humerus. 
Table III - Macroscopic bone alterations (\%) in skeletons of individuals diagnosed in life with renal disease/Controls*

\begin{tabular}{|l|c|c|c|}
\hline $\begin{array}{l}\text { Observation } \\
\text { Bone }\end{array}$ & Resorption & Porosity & $\begin{array}{c}\text { Periosteal } \\
\text { Reaction }\end{array}$ \\
\hline $\begin{array}{l}\text { Humerus } \\
\text { Radius }\end{array}$ & 7 & 0 & 5 \\
Ulna & 1 & $1 / 2$ & 2 \\
Metacarpal & 3 & 1 & 5 \\
Phalanges** & & & 2 \\
$\quad$ - Proximal & 3 & 1 & 2 \\
- Middle & 3 & 1 & 4 \\
- Distal & 2 & 1 & 1 \\
Pelvis & 3 & $1 / 4$ & 17 \\
Femur & 2 & 5 & 22 \\
Tibia & 0 & 3 & 46 \\
Fibula & 1 & 2 & 50 \\
Tarsal & 2 & 2 & 4 \\
Metatarsal & 7 & 4 & 10 \\
IP** & 1 & 2 & 8 \\
Clavicle & 16 & $16 / 4$ & 10 \\
\hline * If no /, then controls were unaffected. \\
** Phalanges: of hand; IP: distal and proximal interphalangeal joints of \\
feet.
\end{tabular}

overhanging edge noted in 27 (Table I). The latter were predominantly $(89 \%)$ pauciarticular (Table II). The most commonly affected joint was the metatarsal phalangeal $(63 \%)$, followed by tarsal metatarsal and metacarpal phalangeal (each at $19 \%)$ and metacarpal carpal (11\%) joints.

\section{Digital tufts}

Alteration in distal phalangeal tufts took three forms: isolated "nicks" (of unclear derivation), clearly post-traumatic, and erosion (Fig. 5). A

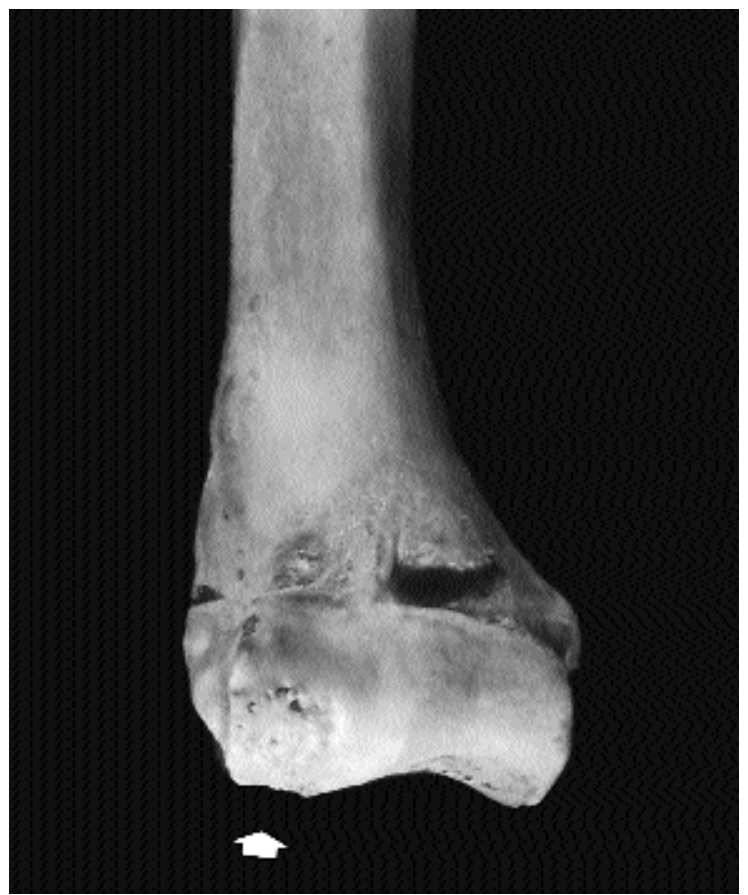

Figure 4 - Osteochondritis (arrow).

"nick" was noted in a single distal tuft in each of 7 individuals. The "nick" appeared as a relatively sharply defined $1 \mathrm{~mm}$ defect in the outer margin. Three individuals had clearly post-traumatic alterations. Only one example of actual tuft erosion was observed.

\section{Periosteal Reaction}

Periosteal reaction was predominantly diaphyseal in distribution. It was noted (Fig. 6) in 71 individuals (Tables II and III). Average number of affect-

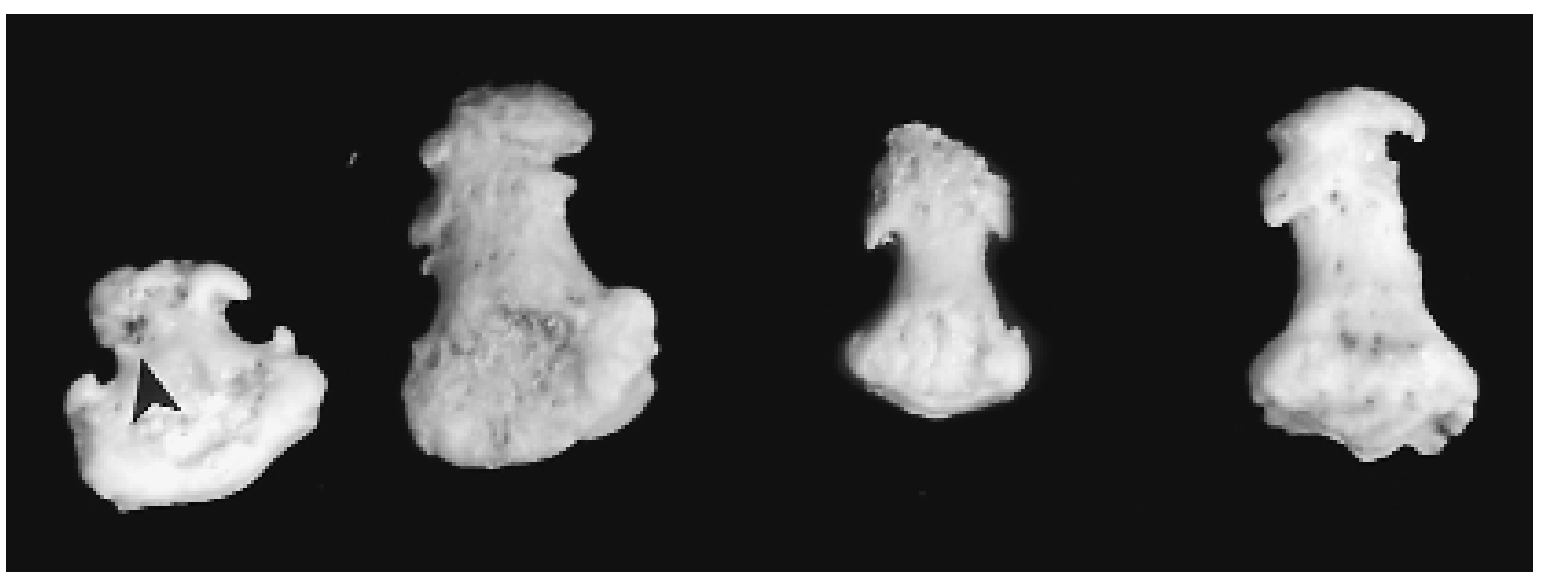

Figure 5 - Isolated "nicks," post-traumatic changes and erosion (arrow). 


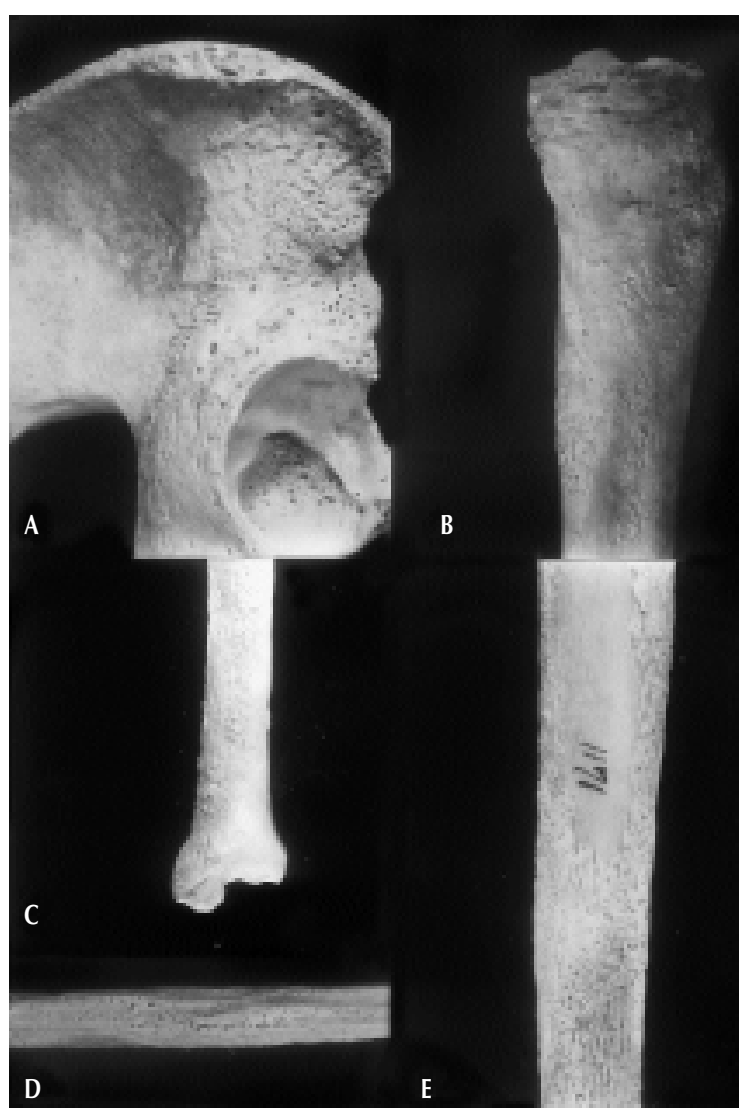

Figure 6 - Periosteal reaction involving pelvis $(A)$, tibia $(B, C, E)$ and fibula (D).

ed bone groups among individuals with periosteal reaction was 2.56. Periosteal reaction, when present, appeared as a surface reaction (Fig. 6), although one individual did have the "applique" form. Diffuse involvement was noted in $30 \%$, with less generalized involvement in $70 \%$. Periosteal reaction was limited to distal diaphyses in only $21 \%$, identical to the percentage of individuals in whom the distal diaphyses were unaffected (spared).

Sabre shin phenomenon was not found. Tibial (periosteal reaction) sparing was common (25 individuals, $35 \%$ ). Tibial involvement was unilateral in $43 \%$ of individuals with periosteal reaction. Femoral periosteal reaction was found in $23 \%$ of individuals in whom the tibiae were unaffected. Periosteal reaction was present on the ischium, ilium and pubis in $24 \%$ of individuals with renal disease.

\section{Leontiasis ossea}

Only individuals under age 70 were affected. Only $49 \%$ of skulls appeared normal. Hypertrophy of facial and cranial bones produced a robust appearance, manifest as large, heavy skulls in $10 \%$ and cranial thickening (observed in cross section) in $12 \%$. Bony overgrowth, mimicking osteomas, was present in $19 \%$ and internal cranial overgrowth was noted in $2 \%$. Widely spaced teeth were present in 5\%. Facial resorption was present in $17 \%$.

\section{Radiologic findings}

Osteopenia (Fig. 7A-D) was present in 46 individuals, with intracortical resorption in 25 . Subperiosteal bone resorption (Fig. 7C-E) was recognized in 4 individuals. There was also a change in the cortical margin of Fig. 7E, opposite to the lesion identified by the white arrow. This observation emphasizes the occasional difficulty distinguishing periosteal reaction from subperiosteal resorption. While there was slight overtubulation of the bone at the junction of the distal and middle thirds, the more proximal portion clearly manifested periosteal reaction. Thus both periosteal reaction and subperiosteal resorption were present in this bone.

Coarsening of trabeculae was noted in 5 individuals (Fig. 7A-D), one of whom had Paget's disease (Fig. 7D). Looser lines (of osteomalacia) were present in one individual (tibia), growth arrest lines in two and bone islands in two (ulna, humerus and tarsal). "Salt and pepper" type bone resorption (Fig. 7G) was an isolated skull finding, characteristic of the secondary hyperparathyroidism in renal osteodystrophy.

Geodes (Fig. 7F) were present in one individual (affecting carpals). Cystic lesions were present in 10 others. The bone surrounding the cystic lesion was osteopenic in 7 of that group, contrasted with three who had preserved peri-lesional bone density. The cystic lesions were distributed to femora (4 individuals), tibia (individuals), pelvic bones ( 2 individuals), wrist bones (4 individuals), humerus ( 1 individual), and metatarsal (1 individual).

Subchondral erosions were noted radiologically in 4 individuals (isolated shoulder, elbow, and metacarpal phalangeal). Marginal erosions were noted radiologically in proximal and distal interphalangeal, wrist, elbow, and metatarsal phalangeal joints.

Periosteal reaction was noted radiologically in only 5 individuals, three of whom also had diagnosed syphilis and one, osteomyelitis (tibia and fibula). The one individual without an alternative 


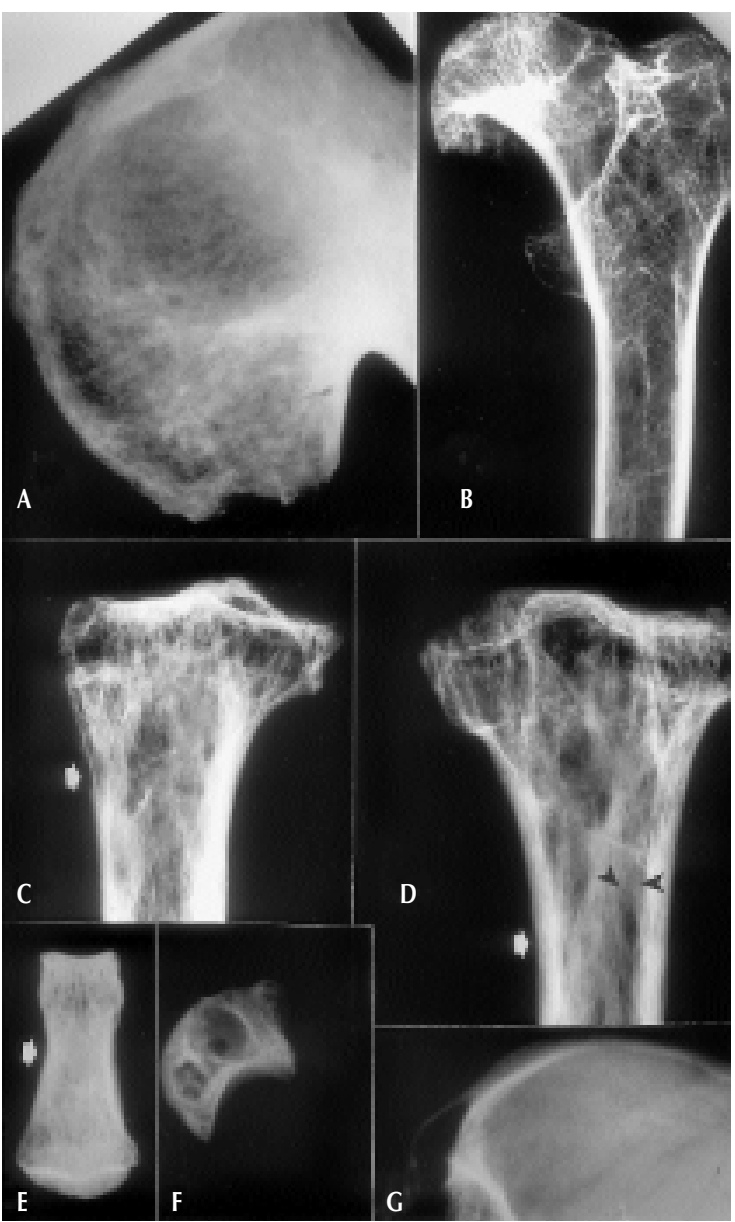

Figure 7 - $X$-rays of innominate $(A)$, femur $(B)$, tibia $(C, D)$, middle phalanx $(\mathrm{E})$, lunate $(\mathrm{F})$, and superior aspect of skull $(\mathrm{G})$. Osteopenia and coarsening of trabeculae are prominent in A-D. Coarsening in D is clearly associated with the "blade of grass" type fronts of resorption (black arrowheads) characteristic of Paget's disease. Subtle subperiosteal bone resorption (white arrows) is noted in $\mathrm{C}, \mathrm{D}$ and $\mathrm{E}$. There is also a change in the cortical margin of E opposite to the lesion identified by the white arrow. This stresses the occasional difficulty distinguishing periosteal reaction from subperiosteal resorption. While there is slight overtubulation of the bone at the junction of the distal and mid thirds, the more proximal portion clearly manifests periosteal reaction. Large cysts (geodes) are present in F. "Salt and pepper" type bone resorption in frontal bone $(\mathrm{G})$ is characteristic of the secondary hyperparathyroidism in renal osteodystrophy.

(to renal disease) etiology of periosteal reaction had femoral involvement with subperiosteal resorption. One individual had generalized periosteal reaction.

Skull radiographs (Fig. 8) revealed prognathism with thick facial bones, developed glabella and hard palate and thick, dense cranial bones. Partial obliteration of nasal sinuses was noted.
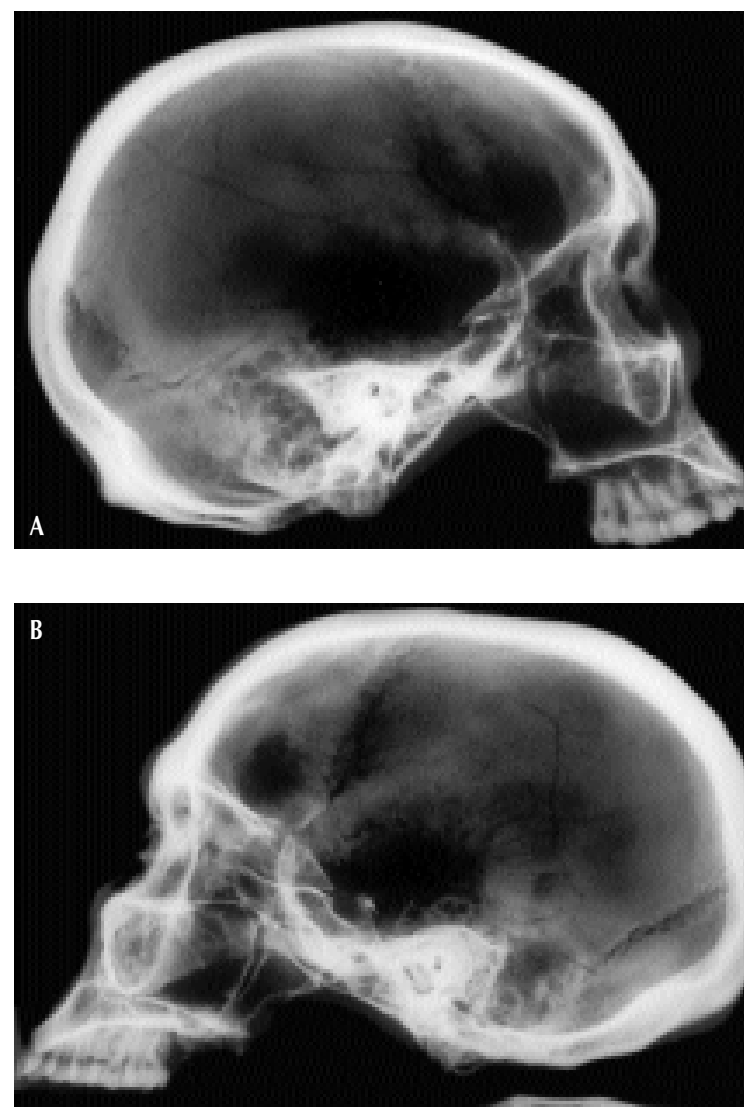

Figure 8 - Lateral x-ray of hemicrania. A. Normal skull. B. Skull of individual with renal osteodystrophy. Increased cranial thickness. Thick facial bones, developed glabella and hard palate. Prognathism.

\section{CONTROLS}

Fifty controls included 26 white males, 16 black males, 2 white females and 6 black females. The average age at death was 50 .

Erosions were noted in 4 individuals. All were marginal in distribution and represented isolated phenomena in any given individual. A cyst was present in only 1 individual. Calcium joint surface deposits were present in 5 individuals. Knees were involved in 4 individuals and ankle, wrist and shoulder, each in one individual. Neither resorptive changes nor subperiosteal resorption were present, although porosity was present in 4 individuals. Eburnation was present in 7 individuals.

Periosteal reaction (predominantly diaphyseal) was noted in 4 individuals, as surface reaction. Periosteal reaction was distributed to one bone group (a bone group was defined by involvement of that bone, whether unilateral or bilateral) in 1 individ- 
ual, 2 in two individuals, and 3 in one individual. Average number of affected bone groups among individuals with periosteal reaction was 2.0.

\section{DISCUSSION}

\section{Osteopenia}

Renal failure was typically associated with osteopenia caused by osteomalacia and hyperparathyroidism (2). Secondary hyperparathyroidism produced increased osteoclastic activity (3). Vitamin D processing disturbance led to osteomalacia (3).

\section{Osteomalacia}

Signs of osteomalacia included linear/ribbon-like radiolucent bands at right angle to bone surface (2). These pseudofractures, diagnostic of osteomalacia (8), are referred to as Looser lines. Cortex was often thinned, with a fuzzy indistinct outline and fuzzy irregular trabeculae (8). The resultant softened bone may become bowed (e.g., tibial/ femoral) (8). Looser lines were present in only one individual in the Hamann-Todd Collection with chronic renal disease and trabecular coarsening in only 4 individuals [1 individual with Paget's disease discounted, as Paget's disease produces trabecular coarsening $(2,7)]$. Thus, osteomalacia would appear to be a poor and unlikely discriminator for recognition of chronic renal disease in pre-dialysis (e.g., archeologic) populations.

\section{Secondary Hyperparathyroidism}

While clinical evidence of secondary hyperparathyroidism was common in chronic renal disease, radiologically detectable osseous changes were relatively rare. Signs have been reported in 5$13 \%$ of dialyzed patients $(4,5,9)$. Findings were typically subtle, with loss of sharpness of osseous borders (especially of terminal phalanges), cortical disruption and endosteal "scalloping" $(4,5)$. Subperiosteal resorption was present in only $4-8 \%$ of clinical samples (5). Observation of subperiosteal bone resorption (Figg. 3 and 7C-E) radiologically in only 4 individuals with chronic renal failure in the Todd Collection was within the reported range. It was therefore an insensitive (4\%) indicator for presence of renal disease.

Brown tumor is a term given to the non-descriptive, lytic lesions of secondary hyperparathyroidism (2). Also called osteitis fibrosa cystica (4), this was recognized as increased cortical porosity, osseous coarsening and cyst formation. At least 7 of the cystic lesions in the Hamann-Todd Collection could possibly be attributable to osteitis fibrosa cystica. However, their isolated nature was at variance with what is reported in the clinical literature (2).

Resorption of digital tufts was reported in 12 of 80 dialysis patients (9). Distal tuft changes, however, were more rare and quite subtle in the HamannTodd Collection. The tuft "nicks" were at the very limit of radiologic detection (unless special high resolution technique is utilized). Notation of a single tuft erosion suggested that it is a very insensitive sign for presence of renal disease in the population.

\section{Porosity}

The significance of porosity (in 16 individuals) is unclear at this time. Porosity is a concept that is difficult to analyze in living individuals (10). This discontinuity of subchondral bone (porosity) is below the resolution of clinical x-rays (2). It therefore cannot be recognized in those $\mathrm{X}$-rays. As the phenomena cannot be detected in life, its significance can only be assumed. Absence of other signs of bone involvement make it difficult to interpret porosity. Large population studies will be required to determine if porosity actually has specificity for any disorder.

\section{Arthritis}

Presence of joint surface calcium deposits (Fig. 2) in 57 individuals and crumbling changes in 21 suggested that the underlying disorder was what has been previously categorized as calcium pyrophosphate deposition disease (CPPD) (11). The latter is a known complication of the hyperparathyroidism of renal osteodystrophy $(4,12)$. The distribution of joint involvement was analogous to that reported for CPPD (11). These observations in the HamannTodd Collection were similar to those reported by Sundaram et al. (9) in clinical populations.

Additional osseous manifestations included geodetype bone cysts (Fig. 7F). They were rarely observed in the Hamann-Todd Collection. These were apparently also manifestations of $\operatorname{CPPD}(2,7)$. "CPPD-like arthritis" is reported by Braunstein et al (12), affecting metacarpal phalangeal joints and wrists, less commonly knees, shoulders and hips, similar. This mirrors findings in the Hamann-Todd collection. As such changes are also common in the general population $(2,11)$, they do not appear to have differential significance for recognition of renal disease. 


\section{Eburnation}

The non-specific finding of severe joint cartilage loss (manifest by osseous eburnation), was noted in 29 individuals with renal disease, contrast with 7 controls. Eburnation simply represents the final stage of cartilage loss from any form of cartilageimpacting/altering arthritis and is without diagnostic implication (at least as to diagnosis).

\section{Avascular necrosis}

Presence of osteochondritis (avascular necrosis) in 4 individuals in the Hamann-Todd Collection (Figure 4) mirrored the 4 of 130 observed by Brown and Gower (13) in clinical populations. Osteochondritis may have some specificity, as it is uncommon (exclusive of avascular necrosis of hips and shoulders) in other disorders, except blood dyscrasias (e.g., sickle cell anemia) $(2,14)$.

\section{Osteosclerosis}

Increased density of bone or osteosclerosis manifested as accumulation of unmineralized trabecular bone in vertebrae, pelvis, ribs, clavicles, and long bone metaphyses (5). This is more common in dialysis patients, because of prolongation of life span (4). The classic manifestation is the so called "rugger jersey" spine, because of the characteristic vertebral endplate sclerosis (4). Frequencies of 9-34\% were reported in dialysis patients $(2,4,5)$. Osteosclerosis was not present among individuals with chronic renal failure in the Hamann-Todd Collection. It is unlikely to be present in archeologic sites, as individuals apparently did not survive sufficiently long (once they developed chronic renal failure) for this to manifest.

\section{Deposition diseases (gout and amyloidosis)}

Other complications of chronic renal disease are gout and amyloidosis (2). Gout, noted in 5\% of clinical populations, occurs because of uric acid accumulation - secondary to interference with its renal excretion $(2,15)$. Amyloidosis (16) appears to be especially related to hemodialysis. Few changes occur within 5 years of chronic renal failure, although $50 \%$ of individuals on dialysis develop it by 10 years. Amyloidosis often complicates chronic inflammatory processes. The acute phase reaction to inflammation sometimes includes a soluble protein. That protein can deposit in body tissues as a space occupying phenomenon or mass of the protein amyloid. The etiology of the spaceoccupying (Fig. 1) lesions (present in 18 individuals, with overhanging edge noted in 27) requires clarification. Although it could represent either disorder, the distribution predominantly to metatarsal phalangeal (63\%), tarsal metatarsal and metacarpal phalangeal (each at 19\%) and metacarpal carpal $(11 \%)$ joints was classic for gout $(2,15)$. It was quite different from that of amyloidosis (2).

\section{Periosteal reaction}

Periosteal reaction was reported in 6-8\% of hemodialysis patients (5). It was often associated with osteitis fibrosa cystica, rib fractures and possibly gout (5). Radiologically-detectable periosteal reaction was a late finding, predominantly limited to individuals receiving dialysis more than two years. Pelvic bones and femora were most commonly affected (radiologically), followed in frequency by tibia, fibula, metatarsals, distal radius and ulna and proximal humerus. The latter often occured as isolated phenomenon (5).

Radiologic recognition of periosteal reaction in only one individual with chronic renal failure represented a frequency slightly lower (Fisher exact test $<0.0001)$ than that reported in dialyzed patients. Periosteal reaction is unlikely to be present (as a radiologically documentable phenomenon) in archeologic populations, as individuals apparently did not survive sufficiently long (once they developed chronic renal failure) for this to manifest.

Macroscopic visual examination of individuals in the Hamann-Todd collection with chronic renal disease, however, revealed a high frequency of periosteal reaction. It was noted in 71 individuals with chronic renal failure (Table III). It was distributed to one bone group in 24 individuals, 2 in 16, 3 in 14, 4 in 11,5 in 4, 7 in 1 , and 13 in 1 individual. Average number of affected bone groups among individuals with periosteal reaction was 2.56 . This contrasted with 2.0 in the "control" group, in whom polyostotic involvement was not found.

Periosteal reaction among individuals with renal disease was distinguishable, on a population basis, from treponemal disease (17). Sabre shin reaction was not found. Tibial (periosteal reaction) sparing, extremely rare in treponemal disease, was common in renal disease (25 individuals, $35 \%$ ). Pelvis periosteal reaction was common in renal disease (24\%), contrasted with its rarity in treponemal disease. Periosteal reaction was less polyostotic and upper extremities more spared than has been observed in yaws. Periosteal reaction in renal disease involved the hands and feet to a much greater extent than noted in syphilis.

Periosteal reaction among individuals with chronic 
renal disease was also distinguishable from hypertrophic osteoarthropathy (HOA) on the basis of extent of skeletal involvement (2.5 in renal disease, versus 3.7 in HOA), low frequency of "applique" form, high frequency of unilateral tibial involvement and distal diaphyseal sparing in renal patients (18, 19). Tibia were involved in $99 \%$ of individuals with HOA, compared to only $65 \%$ with renal disease. Upper extremity involvement in chronic renal disease was seen less often than in HOA, while pelvic bone involvement was significantly greater. Periosteal reaction was predominantly a surface reaction, diffuse in $30 \%$. One-fifth of individuals with periosteal reaction had distal diaphyseal sparing, contrasted with rarity of the latter in $\operatorname{HOA}(18,19)$. What did the periosteal reaction represent? Was this a macroscopic correlate of what Mankin (8) described radiologically as cortical thinning "with a fuzzy indistinct outline and fuzzy irregular trabeculae?" The answer awaits histologic studies, not pursuable on the Hamann-Todd collection. Further, this work raises an intriguing possibility. Could what is macroscopically interpreted as periosteal reaction actually be part of osteomalacia? Cortical thinning with a fuzzy indistinct outline and fuzzy irregular trabeculae was Mankin's (8) description of osteomalacia. Perhaps further study will lead to better understanding of what we categorize as periosteal reaction.

\section{Leontiasis ossea}

Lee et al (20) reported a series of 5 individuals with adolescent onset renal disease who developed leontiasis ossea. Progressive hypertrophy of facial and cranial bones with widely spaced teeth were reported, as noted in the present series. While her radiographs revealed nodular areas of sclerosis and widening of the diploic plate, the present study revealed the macroscopic correlate: a pseudo-osteomatous appearance. The robust facial appearance of the individuals noted in the current study reflected hypertrophy of the maxillary bone and mandible, observed by Lee et al (20). Partial obliteration of maxillary sinuses was also noted. This appeared to be a manifestation of renal disease, limited to those who have early onset of kidney damage.

\section{Differential diagnosis}

It must always be considered that skeletal findings in a phenomenon (e.g., chronic renal failure), with a myriad of etiologies, may actually represent the impact of the etiology, rather than the result of the subsequent renal failure. Thus, skeletal alterations in chronic renal failure may result from disorders or their treatment (e.g., possibly sulfa antibiotics used to treat infections, syphilis, salicylic acid used to treat pain produced by bone-altering diseases, blood dyscrasias such as multiple myeloma and amyloidosis) (2), rather than the nephropathy itself. Looser line-type pseudofractures are characteristic of osteomalacia. Differential diagnosis of such pseudofractures includes other derivations of osteomalacia (e.g., fibrous dysplasia-induced or neurofibromatosis-induced) and the stress fractures of Paget's disease (8).

\section{Population frequency issues}

Rutecki (21) reported 3 cases categorized as nephrotic syndrome and 2.8 categorized as chronic renal failure per 100,000 population. Most of the chronic nephrotic syndrome cases derived from individuals with acute glomerulonephritis. Rutecki (21) noted that $10 \%$ of acute glomerulonephritis $(20$ cases per 100,000$)$ proceeded to nephrotic syndrome. Given the removal (by mortality) of individuals from prevalence data and absence of effective medical intervention in the early part of this century (22), the number of cases observed in the Hamann-Todd collection appears quite representative of population expectations. While chronic renal disease has many potential causes, it still is relatively infrequent in the population. Even in what might be considered a selected population (Hamann-Todd Collection), it only represented 3\% of skeletons.

\section{Can kidney disease be recognized from examination of skeletons?}

Examination of individual components of renal bone disease indicates the problem. Osteomalacia would appear to be a poor and unlikely discriminator for recognition of chronic renal disease in pre-dialysis (e.g., archeologic) populations. Brown tumors are too non-descriptive in appearance in pre-dialysis patients to allow their use as identifiers for renal disease in archeologic populations. Similarly, digital tuft lesions are of unknown specificity and are too infrequent for use in recognizing renal disease in archeologic samples. Osteosclerosis was not present among individuals with chronic renal failure in the Hamann-Todd Collection and is therefore unlikely to be present in archeologic sites. Prior to dialysis, individuals with chronic renal disease do not appear to have survived sufficiently long to manifest significant recognizable diagnostic osseous alterations. 
Osteochondritis of joints other than hips and shoulders may have some specificity, as it is uncommon in most other disorders. Given its low frequency in renal disease and lack of specificity, it would not appear to be a viable indicator for epidemiologic study of archeologic samples.

Radiologically recognized subperiosteal bone resorption may have greater specificity, but is relatively uncommon. Given even the most ambitious anticipation of renal disease in the population, a sample size of over 500 would likely be required to recognize presence of any chronic renal disease in that population (if radiologic subperiosteal reaction were used as the identifier). Macroscopic recognition was more common. Perhaps examination of clavicles, manus and pes (for subperiosteal resorption) might help in recognition of the disease. However, large populations will have to be examined, to assess the specificity of that finding. Could joint surface calcium deposits and crumbling changes [previously categorized as calcium pyrophosphate deposition disease $(9,11,23)]$ be utilized as indication of presence of renal disease in the population? Unfortunately, such changes are common in the general population $(2,11)$, even in absence of renal disease.

Periosteal reaction (as a radiologically documentable phenomenon) is unlikely to be present in archeologic sites, as individuals apparently did not survive sufficiently long (once they developed chronic renal failure) for this to manifest.

However, a high frequency of periosteal reaction was recognized macroscopically, usually affecting one or two bone groups. Pelvic bone changes were especially common, suggesting the possibility that this could represent a potential identifier for recognition of renal disease. Space-occupying lesions also were common. They appeared to represent gout. High frequency of such lesions might be a clue to diagnosis. Other than genetically predisposed groups (e.g. Maori) (15), gout should be relatively uncommon in the population - unless there is a specific disease (e.g., renal) predisposition. Presence of subperiosteal resorption (Fig. 7C-E) would suggest the diagnosis of renal disease, but, given its rarity, was a very insensitive indicator. While macroscopic periosteal reaction was common in chronic renal disease, associated calcific joint changes (CPPD) allowed recognition of renal etiology, even if the subperiosteal resorption (apparently specific for the hyperparathyroidism of renal disease) was not present. The pattern of joint surface alteration and periosteal reaction may facilitate recognition of chronic renal disease in the osseous record.

Recognition of increased frequency of apparent osteomas in individuals with robust facial features should stimulate investigation for other manifestations of renal disease. Presence of facial bone thickening and prognathism should also stimulate consideration of renal disease. As leontiasis ossea was limited to young individuals in the current study and that reported in clinical population by Lee et al (20), leontiasis ossea would appear to be another potential sign, suggesting investigation for other manifestations of early onset renal disease.

\section{ACKNOWLEDGEMENTS}

We wish to acknowledge Dr. Bruce Lattimer and Lyman Jellema and the Cleveland Museum of Natural History for logistical and technical support in examining the Haman-Todd Collection.

\begin{abstract}
SUMMARY
The possible osseous effect of kidney dysfunction was evaluated in a modern skeletal population for future use in assessment of archeologic samples. Frequency and distribution on the bones of cysts, articular surface alterations, subperiosteal resorption, porosity, osteochondritis, digital tuft alteration and periosteal reaction were recorded in 94 individuals with known kidney failure in the Hamann-Todd collection. Independent radiologic analysis was also pursued. The results were compared with a control sample. The pattern of joint surface alteration and periosteal reaction may facilitate recognition of chronic renal disease in the osseous record. Subtle manifestations of leontiasis ossea are present in the form of cranial thickening and increased cranial size and weight, but teeth spacing are rare. Pseudo osteomatous lesions are common. This study perhaps explains the apparent rarity of actual leontiasis ossea.
\end{abstract}

Parole chiave: Malattie renali, lesioni osteolitiche, rachitismo, osteomalacia, iperparatiroidismo, reazione periostale, patologia scheletrica.

Key words: Renal disease, lytic lesions, rickets, osteomalacia, hyperparathyroidism, periostal reaction, skeletal patho$\log y$ 


\section{REFERENCES}

1. Cobb WM. Human Archives. Doctoral Dissertation. Western Reserve University, Cleveland, Ohio, 1932.

2. Resnick D, Niwayama G. Diagnosis of Bone and Joint Disorders. Philadelphia: Saunders, 1988.

3. Amling M, Grote HJ, Vogel M, Hahn M, Delling G. Three-dimensional analysis of the spine in autopsy cases with renal osteodystrophy. Kidney Int 1994; 46: 73343.

4. Eastwood JR, Bordier PJ, de Wardener HE. Some biochemical, histological, radiological and clinical features of renal osteodystrophy. Kidney Int 1973; 4: 128-40.

5. Massry SG, Bluestone R, Klinenberg JR, Coburn JW Abnormalities of the musculoskeletal system in hemodialysis patients. Semin Arthritis Rheum 1975; 4: 321-49.

6. Snapper I. Medical Clinics on Bone Diseases. New York: Interscience Publishers, 1943.

7. Rothschild BM, Martin L. Paleopathology: Disease in the Fossil Record. London: CRC Press, 1993.

8. Mankin HJ. Rickets, osteomalacia and renal osteodystrophy. J Bone Joint Surg 1974; 56A: 101-28.

9. Sundaram M, Wolverson MK, Heiberg E, Grider RD. Erosive azotemic osteodystrophy. Am J Roentgenol 1981; 136: 363-7.

10. Rothschild BM. Porosity: curiosity without diagnostic significance. Am J Phys Anthropol 1997; 104: 529-33.

11. Rothschild BM, Woods RJ, Rothschild C. Calcium pyrophosphate deposition disease: description in defleshed skeletons. Clin Exp. Rheumatol 1992; 10: 557-64.

12. Braunstein EM, Menerey K, Martel W, Swartz R, Fox IH. Radiologic features of a pyrophosphate-like arthropathy associated with long-term dialysis. Skeletal Radiol 1987; 16: 437-41.

13. Brown EA, Gower PE. Joint problems in patients on main- tenance hemodialysis. Clin Nephrol 1982; 18: 247-50.

14. Hershkovitz I, Rothschild BM, Latimer B, Dutour O, Rothschild C, Jellema LM. Recognition of sickle cell anemia in skeletal remains. Am J Phys Anthropol 1997; 104: 213-26.

15. Rothschild BM, Heathcote GM. Characterization of gout in a skeletal population sample: presumptive diagnosis in Micronesian population. Am J Phys Anthropol 1995; 98: 519-25.

16. Hurst NP, van den Berg R, Disney A, Alcock M, Albertyn L, Green M, et al. 'Dialysis related arthropathy:'a survey of 95 patients receiving chronic haemodialysis

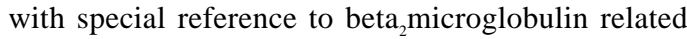
amyloidosis. Ann Rheum Dis 1989; 48: 409-20.

17. Rothschild BM, Rothschild C. Treponemal disease revisited: skeletal discriminators for Yaws, Bejel, and venereal syphilis. Clin Infect Dis 1995; 20: 1402-8.

18. Rothschild BM, Rothschild C. Nature and distribution of periosteal reaction in hypertrophic osteoarthropathy (HOA). Amer J Phys Anthropol Suppl 1997; 24: 200-1.

19. Rothschild BM, Rothschild C. Recognition of hypertrophic osteoarthropathy in skeletal remains. J Rheumatol 1998; 25: 2221-7.

20. Lee VS, Webb MS Jr, Martinez S, McKay CP, Leight GS Jr. Uremic leontiasis ossea: "Bighead" disease in humans? Radiologic, clinical and pathologic features. Radiology 1996; 199: 233-40.

21. Rutecki GW. Nephrotic syndrome. In Damkbro MR (ed.): Griffith's 5 Minute Clinical Consultant. Baltimore: Williams and Wilkins, 1997: 714-5

22. Fishberg AM. Hypertension and Nephritis. 3rd ed. Philadelphia: Lea and Febiger, 1934.

23. Sethi D, Morgan TC, Brown EA, Cary NR, Erhardt CC, Pazianas M, et al. Dialysis arthropathy: a clinical, biochemical, radiological and histological study of 36 patients. Q J Med 1990; 77: 1061-82. 